\title{
On the Tensile Strength of Granite at High Strain Rates considering the Influence from Preexisting Cracks
}

\author{
Mahdi Saadati, ${ }^{1,2}$ Pascal Forquin, ${ }^{3}$ Kenneth Weddfelt, ${ }^{2}$ and Per-Lennart Larsson ${ }^{1}$ \\ ${ }^{1}$ Department of Solid Mechanics, KTH Royal Institute of Technology, 10044 Stockholm, Sweden \\ ${ }^{2}$ Atlas Copco, 70225 Örebro, Sweden \\ ${ }^{3} 3$ SR Laboratory, Grenoble-Alpes University, 38041 Grenoble, France
}

Correspondence should be addressed to Per-Lennart Larsson; pelle@hallf.kth.se

Received 4 February 2016; Accepted 14 June 2016

Academic Editor: Konstantinos I. Tserpes

Copyright (C) 2016 Mahdi Saadati et al. This is an open access article distributed under the Creative Commons Attribution License, which permits unrestricted use, distribution, and reproduction in any medium, provided the original work is properly cited.

\begin{abstract}
The dynamic tensile behavior of granite samples, when some preexisting cracks are introduced artificially, is investigated. Spalling tests using a Hopkinson bar are performed and strain rates of $\sim 10^{2} 1 / \mathrm{s}$ are obtained in both specimen types (with and without initial cracks). This experimental technique is employed being of the same order as strain rates in rock materials during percussive drilling, the application of interest here. The dynamic tensile responses of both sample-sets are compared using the velocity profile measured on the free-end of the sample. Furthermore, an anisotropic damage model based on the concept of obscuration probability describes the response without preexisting cracks. Here, a term of cohesive strength in obscuration zones is added to accurately handle the softening behavior of the material in tension. Results from the spalling tests are used to validate the model prediction of the dynamic tensile strength and also to calibrate the cohesive model parameters. Damaged elements are numerically introduced in the finite element calculations simulating the spalling experiments performed on predamaged samples. The results are compared with the experimental ones. Good agreement is obtained showing that a two-scale approach may constitute a suitable method to simulate numerically the tensile response of predamaged granite.
\end{abstract}

\section{Introduction}

The strain rate dependency of the mechanical response in brittle materials has been widely investigated in the literature. Considerable rate dependency is reported especially in the case of tensile strength [1-4]. There exists a threshold level of strain rate beyond which the tensile strength increases by increasing the strain rate. This threshold level is explained to be connected to the size of heterogeneity in the material $[1,5]$ and material defects size, population, and distribution [6,7]. Direct tension test with split-Hopkinson bar (SHB) has been used to study the tensile strength for strain rates between $10^{-1}$ and $10^{1} 1 / \mathrm{s}[3,8]$. In some cases, indirect tensile strength is measured by means of a Brazilian disc together with splitHopkinson pressure bar (SHPB) apparatus $[9,10]$. Inspired from the classical SHPB method, spalling test with Hopkinson bar is a suitable technique to measure the tensile strength of brittle materials at strain rates between $10^{1}$ and $10^{2} 1 / \mathrm{s}[2,4]$. The main idea in this test is that the impact of the projectile induces a compressive wave that propagates through the bar and is mainly transferred to the specimen. This wave is reflected as a tensile wave from the free surface of the specimen that leads to damaging of the material.

There is a wide range of applications pertinent to the dynamic tensile behavior of brittle materials from blasting in open quarries and concrete structures exposed to impact loading to screen rupture of cell phones due to free fall. Percussive drilling, which is the application of interest in this investigation, is just one of them. The main goal in this work is to develop a reliable numerical tool for simulating the rock fragmentation mechanism during percussive drilling. In modeling such problems, a constitutive model is needed to cover both the tensile behavior of the brittle materials at high strain rate, because of the rapid indentation, and also confined compression behavior that occurs underneath the indenter. The Krieg, Swenson, and Taylor- [11, 12] (KST-) Denoual, Forquin, and Hild $[6,7]$ (DFH) model is adopted to perform such analysis. This material model is composed of a 
plasticity model (KST) to simulate the compressive behavior of geomaterials accounting for the effect of hydrostatic and deviatoric parts of the stress tensor. Also the fragmentation process in tensile loading, due to the opening of cracks, is defined by using an anisotropic damage model (DFH). This model is based on a probabilistic approach describing the dynamic fragmentation of the brittle materials. It should be mentioned that the original DFH model (with no cohesion strength in obscuration zones) enables predicting the dynamic tensile strength of the brittle materials, and the main model parameters are obtained from a set of quasi-static experiments [6, 7]. Saadati et al. [13, 14] applied the KST-DFH model on granite and investigated the rock fragmentation process and the force-penetration response at percussive drilling. The KST-DFH model parameters for Bohus granite have been determined based on previously reported experimental results [15]. It was shown that preexisting cracks in granite have a significant effect on its mechanical response and the fracture pattern at impact loading.

Spalling tests are performed to investigate the dynamic tensile behavior of Bohus granite. As the DFH model predicts the dynamic tensile strength of the brittle materials at high strain rates, this work can be seen as a validation step for the model prediction of the granite tensile strength. The strain rate in the rock during the percussive drilling process is in order of $10^{2} 1 / \mathrm{s}$ based on previous numerical simulations [13]. This is the same order as the strain rates in the rock material during the spalling tests with Hopkinson bar performed in this investigation and therefore makes the spalling experiment an appropriate tool to verify the rate dependency of the material response at dynamic tensile loading. Furthermore, a cohesive strength is added to the original DFH model $[16,17]$ to more accurately deal with the postpeak behavior of the material at tensile loading. Hence the results from the spalling tests are used to calibrate the cohesive model parameters in a dynamic situation.

The experimental results from the spalling tests on Bohus granite are presented. The dynamic tensile strength of the material (without preexisting cracks) is measured and compared with the quasi-static results. When there are cracks in the specimens that are introduced in addition to the material default cracks and defects, called structural cracks in this work, the material response changes considerably. The effect of the structural cracks on the mechanical response and the fracture pattern in Edge-On Impact (EOI) tests, that is, impact of an aluminum projectile onto a rock slab, was previously studied $[13,14]$. When it comes to drilling application, these cracks can be introduced in the rock during drilling due to either former impact of the drill bit or use of methods such as microwave and laser. It was shown that the preexisting structural cracks facilitate the drilling process regardless of their orientation [14]. In order to investigate the effect of these cracks on the dynamic tensile response of the material, some of the spalling specimens were exposed to coarser mechanical loading during the cutting process in order to introduce new cracks to the material. In the present work spalling tests have been performed also on such specimens with preexisting structural cracks and it is shown that the dynamic tensile behavior changes considerably. Numerical modeling of the

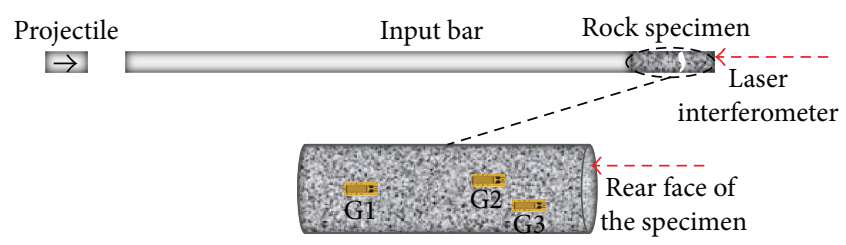

FIGURE 1: Spalling experiment setup with Hopkinson bar.

spalling tests is performed and the results are compared with the experimental ones. The DFH model together with a cohesive strength is used for this purpose. The cohesive model parameters are calibrated based on the experimental results performed on granite without preexisting cracks. In the case of specimens with preexisting structural cracks, these cracks are introduced to the numerical samples by means of sets of predamaged finite elements randomly distributed in the sample. It is shown that the numerical results are in good agreement with the experimental ones.

\section{Experimental Investigation and Results Pertinent to the Tensile Strength of Granite at High Strain Rates}

2.1. Experimental Setup with Hopkinson Bar. Spalling test with Hopkinson bar is suggested as a suitable technique to measure the tensile strength of brittle materials at strain rates between $10^{1}$ and $10^{2} 1 / \mathrm{s}[2,4]$. As is stated before, the numerical modeling of percussive drilling that was previously performed in [13] gives the tensile strain rates in the rock in order of $10^{2} 1 / \mathrm{s}$. It should be mentioned that, in order to obtain this tensile strain rate from the numerical simulation of percussive drilling, the maximum positive principal stress was used from the simulation with only the KST plasticity model (in order to evaluate the level of tensile strain rate in a finite element without influence from damage).

Accordingly, the spalling test with Hopkinson bar is an appropriate method to investigate the dynamic tensile behavior of the material in the interesting range of strain rates pertinent to percussive drilling. The experimental setup used in this work is shown in Figure 1. It consists of a Hopkinson bar made of high-strength aluminum, an aluminum projectile with a spherical cap-end, which is optimized to induce more homogenous tensile stress [4], and the rock sample that is well attached to the bar to increase the wave transmission. The rock specimen is instrumented with strain gauges to record the strain data and also a laser interferometer is directed toward the free surface of the specimen to measure the rear face velocity. The main idea is that the impact of the projectile induces a compressive pulse that travels along the bar and is mainly transferred to the rock specimen. When the compressive wave reaches the free surface of the sample, it is reflected as a tensile wave that propagates in the opposite direction and leads to failure if the tensile strength of the material is passed. Using the laser velocity profile, one can obtain the dynamic tensile strength of the material from the 


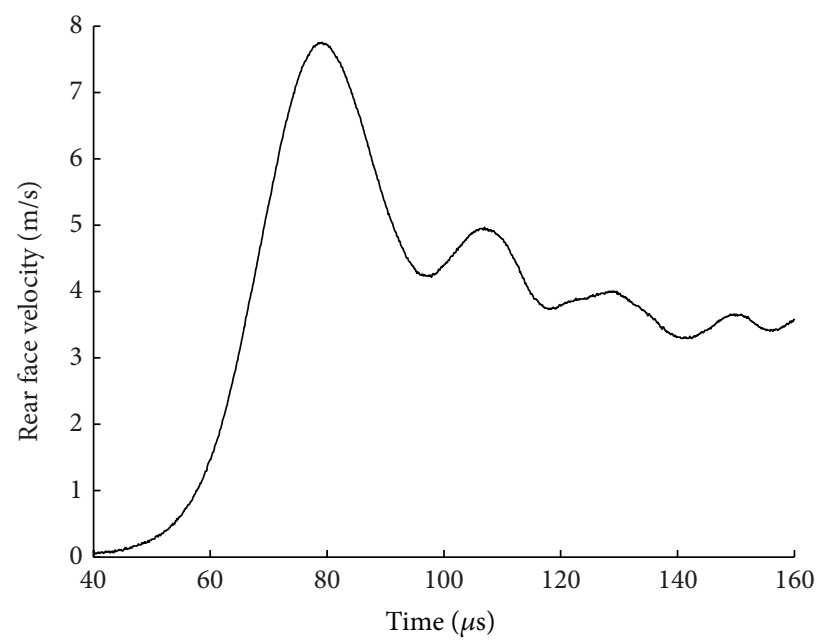

(a)

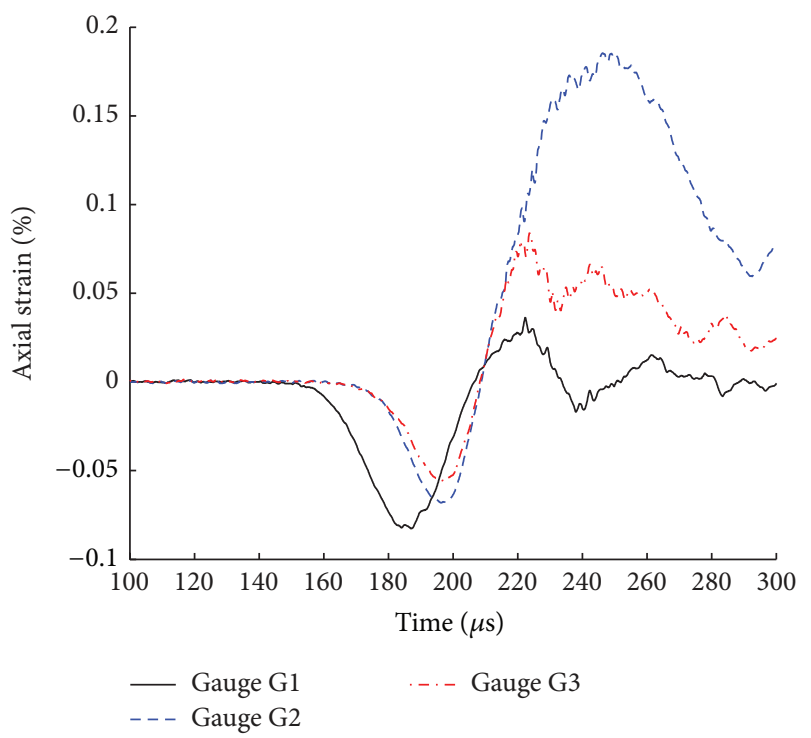

(b)

FIGURE 2: Spalling test results for a specimen without preexisting cracks. Rear face velocity profile from the laser (a) and strain data from the three strain gauges (b).

Novikov formula [18] assuming a linear-elastic behavior of the tested material prior to the peak strength.

2.2. Spalling Test on Granite. The results from the spalling tests are presented in this section. A typical result for both the rear face velocity (obtained from the laser) and the strain data (obtained from the strain gauges) is shown in Figure 2. Three strain gauges (G1, G2, and G3) of length $20 \mathrm{~mm}$ are placed at a distance of $116 \mathrm{~mm}, 45 \mathrm{~mm}$, and $35 \mathrm{~mm}$ from the rear face of the specimen, respectively. The projectile impact velocity in this case was $7.3 \mathrm{~m} / \mathrm{s}$. Based on the Novikov et al. [18] approach, one can relate the dynamic tensile strength of the material to the pullback velocity (the difference between the maximum speed and the speed corresponding to rebound; see Figure 2) assuming a linear-elastic behavior of the material before reaching the tensile ultimate strength:

$$
\sigma_{\text {dyn }}=\frac{1}{2} \rho C_{0} \Delta V_{\mathrm{pb}}
$$

where $\rho=2660 \mathrm{~kg} / \mathrm{m}^{3}$ is the density, $C_{0}=4050 \mathrm{~m} / \mathrm{s}$ is the one-dimensional wave velocity in the material, and $\Delta V_{\mathrm{pb}}=$ $3.5 \mathrm{~m} / \mathrm{s}$ is the pullback velocity. A dynamic tensile strength of $18.9 \mathrm{MPa}$ is obtained (the strain rate is about $701 / \mathrm{s}$ ) in this test using the Novikov et al. [18] approach. The quasi-static tensile strength of the specimen with the same size is reported as about $8 \mathrm{MPa}$ [15].

Furthermore, the nominal stress level $(E \varepsilon)$ obtained from the incident wave data at strain gauge G1 is shifted in the time direction and compared to the one from the rear face velocity data using (1); see Figure 3. The results are very close in the prepeak and early postpeak regions which indicate that the assumption of linear-elastic behavior before damage initiation is valid. This assumption can be further validated

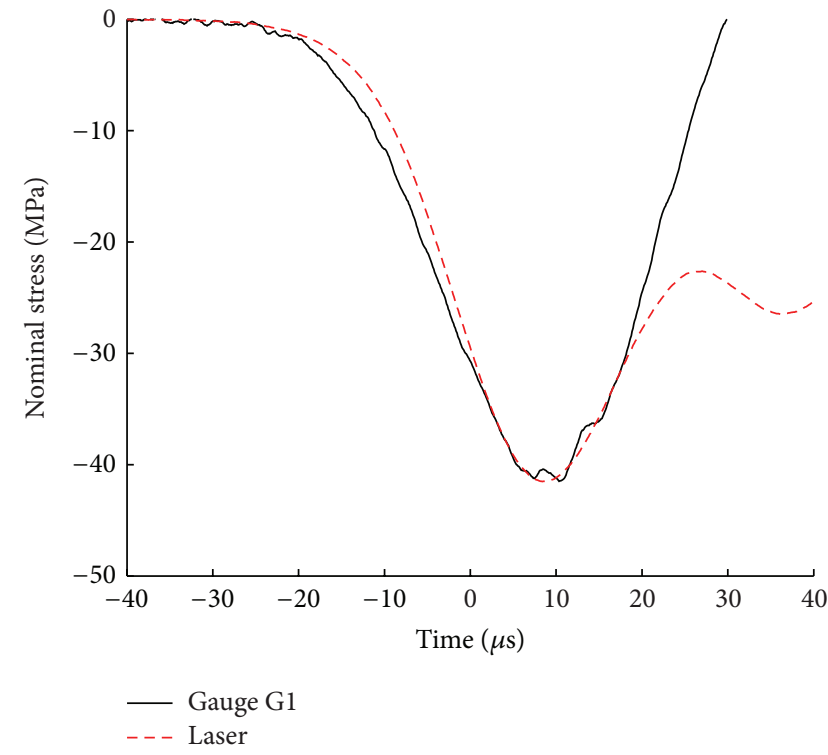

FIgURE 3: Nominal stress obtained from gauge G1 $(E \varepsilon)$ and based on rear face velocity $\left((1 / 2) \rho C_{0} V\right)$ in a specimen without preexisting cracks.

by looking at the stress-strain data obtained earlier from the flexural test on the material [15].

2.3. Effect of Preexisting Structural Cracks on the Results. The effect of the preexisting cracks on the mechanical response and the fracture pattern in Edge-On Impact (EOI) tests, that is, impact of an aluminum projectile onto a rock slab, was previously studied $[13,14]$. In order to investigate the effect of these cracks on the dynamic tensile response of the material, some of the spalling specimens were subjected to coarser 


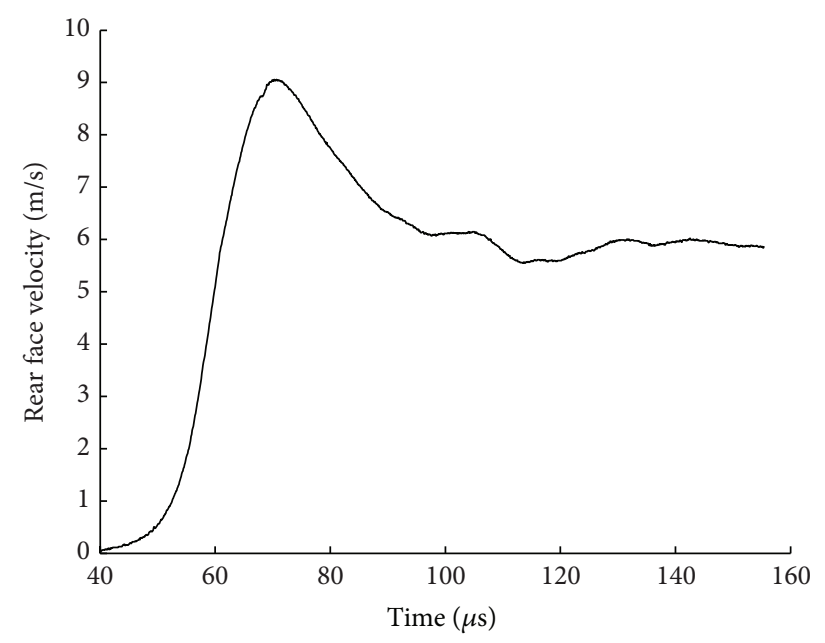

(a)

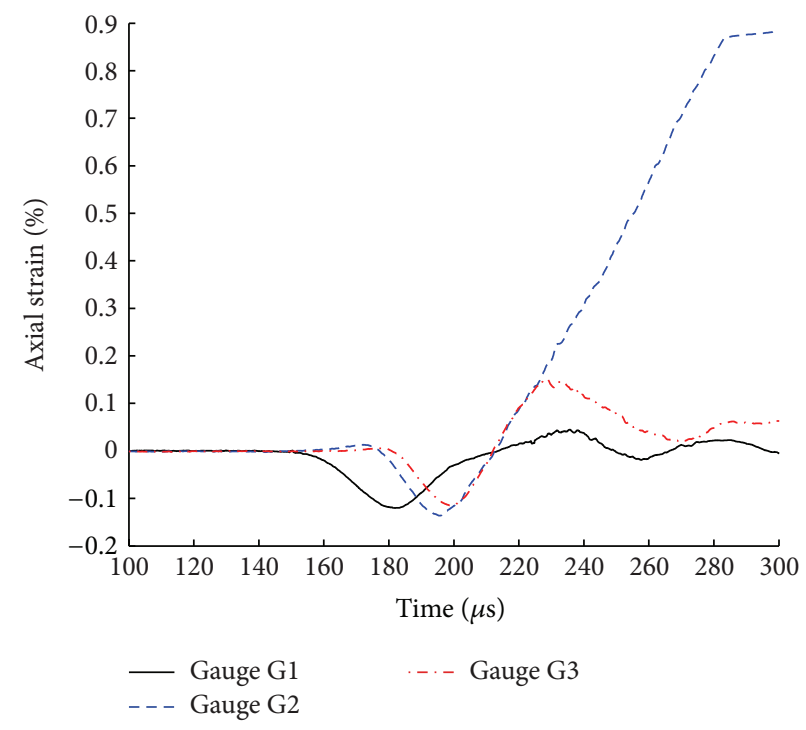

(b)

FIGURE 4: Spalling test results for a specimen with preexisting structural cracks. Rear face velocity from the laser (a) and strain data from the three strain gauges $(\mathrm{b})$.

mechanical loading during the cutting process. This introduced new cracks in the specimens in addition to the cracks and defects that are present in the material by default. These newly introduced cracks in the specimen are hereafter called structural cracks as they are not part of an intact material. To quantify the amount of these cracks, one can perform, for example, quasi-static tensile test and measure the effective stiffness reduction of the specimen. Quasi-static tensile tests were performed on some of the samples and average effective stiffness of about $30 \mathrm{GPa}$ was obtained instead of $52 \mathrm{GPa}$ that is the average effective stiffness of the intact specimens.

When preexisting structural cracks are present in the specimen, the dynamic response of the material during a spalling test changes considerably. A typical result of the spalling test with preexisting structural cracks is shown in Figures 4 and 5 . Strain gauges $\mathrm{G} 1(L=20 \mathrm{~mm}), \mathrm{G} 2(L=$ $30 \mathrm{~mm})$, and $\mathrm{G} 3(L=20 \mathrm{~mm})$ are placed in a distance of $120 \mathrm{~mm}, 61 \mathrm{~mm}$, and $41 \mathrm{~mm}$ from the rear face of the specimen, respectively. The projectile impact velocity in this case was $8.0 \mathrm{~m} / \mathrm{s}$ and the specimen density and $1 \mathrm{D}$ wave speed were $\rho=2671 \mathrm{~kg} / \mathrm{m}^{3}$ and $C_{0}=4400 \mathrm{~m} / \mathrm{s}$, respectively. There are three main differences in these results compared to the intact specimen presented in the previous section. First, in the prepeak region (see Figure 5, region I), the structural cracks in the material are partly closed when the compressive stress travels through the specimen leading to slightly larger difference between gauge G1 and rear face velocity (converted into stress level in Figure 5) contrary to the case of an intact specimen. This is mainly due to nonlinear material behavior in compression that is related to presence of the structural cracks. Secondly, in the early postpeak region (see Figure 5, region II), the nominal stress level obtained from the incident wave at gauge G1 (calculated as $E \varepsilon$ ) is not close to the one obtained from the rear face velocity (calculated as $\left.(1 / 2) \rho C_{0} V\right)$. It is most probably due to the fact that

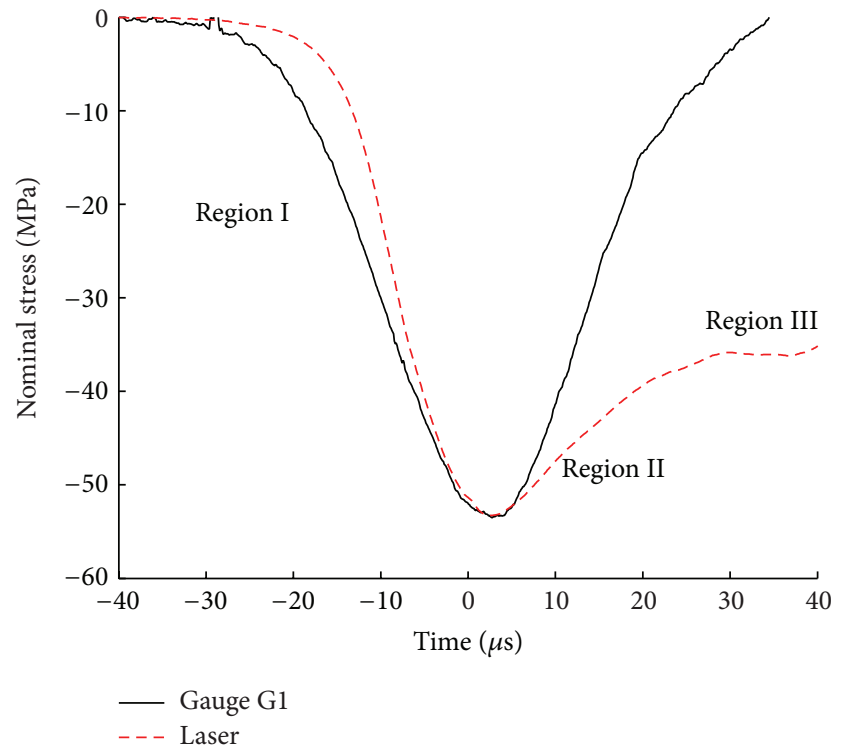

FIGURE 5: Nominal stress obtained from gauge G1 $(E \varepsilon)$ and based on rear face velocity $\left((1 / 2) \rho C_{0} V\right)$ in a specimen with preexisting structural cracks.

the reflected incident wave from the free surface of the specimen experiences some partial reflection when it reaches the surfaces of the structural cracks. It also indicates that the Novikov linear-elastic assumption is not valid in this case. Thirdly in the postpeak region of rear face velocity (Figures 4(a) and 5, region III), the rebound phenomenon is not seen or is negligible in these specimens and the rear face velocity curve is more plateau-like in this section. This is most probably due to the fact that when rebounding should occur due to generated waves from initiated final fracture 
planes, the waves are blocked between the structural cracks and cannot reach the free surface. Accordingly, the structural cracks generate a damping effect in this case that prevents the rebounding phenomenon.

It should be mentioned that the measurement from gauge G2 seems to be extremely high in the tensile part. The reason for this could be that this gauge was glued near one of the structural cracks in which the tensile axial strain gets locally large. The pullback velocity in this test is $\Delta V_{\mathrm{pb}}=3.0 \mathrm{~m} / \mathrm{s}$ and a dynamic tensile strength of $17.4 \mathrm{MPa}$ is obtained (the strain rate is about $1001 /$ s) if one uses the Novikov et al. approach [18]. However, it should be mentioned that the Novikov et al. approach [18] is invalid in this case as the tensile behavior prior to the ultimate stress is not linear-elastic.

\section{Numerical Modeling}

3.1. Constitutive Model and Results. The fragmentation process in brittle materials exposed to dynamic loading, with particular application to percussive drilling, is of most interest in this investigation. The stress state in the material beneath the drilling tool consists of both compressive and tensile stresses. It is well known that brittle materials such as rocks behave differently in compression and tension. Therefore the constitutive model for these materials, to account for such types of phenomena, should include this difference and should be able to distinguish between the two different stress sign dependent responses. For this reason and based on a previous investigation [13], the KST-DFH constitutive model is selected to deal with the fragmentation modeling in brittle materials due to dynamic loading.

The KST-DFH material model is composed of two separate parts in order to deal with both compressive and tensile responses of the material. A plasticity model (KST) is employed to simulate the compressive behavior of geomaterials accounting for the effect of hydrostatic and deviatoric parts of the stress tensor. The fragmentation process, due to the opening of cracks, is defined by using a damage model $(\mathrm{DFH})$, which is explained in detail in $[6,7]$. In the spalling test, however, the level of compressive stresses is not high enough to induce any plastic deformation. Therefore the main emphasis in this investigation with spalling tests is to validate the DFH part of the constitutive model that deals with the dynamic tensile behavior of the material.

In the DFH model, defects with different sizes and orientations are assumed to be randomly distributed within the brittle material. Under static loading the weakest defect is triggered leading to a rapid failure of the sample. Consequently the failure stress is a random variable. Accordingly, a probabilistic approach may be employed to explain the material response to tensile loading at high strain rates. The weakest link theory and Weibull model are adopted as a framework for the damage model $[7,19,20]$. The model covers the tensile behavior of brittle materials from low to high loading rates. At low loading rate conditions, the fracture process is generally the consequence of the initiation and growth of a single crack. This single crack is created from the activation and propagation of the weakest defect in the material. Therefore a Weibull model is adopted to explain this probabilistic response at low loading rates. Using a Poisson point-process framework, the weakest link assumption, and a Weibull model, the failure probability $P_{F}$ is given by

$$
P_{F}=1-\exp \left[-Z_{\mathrm{eff}} \lambda_{t}\left(\sigma_{F}\right)\right]
$$

where $Z_{\text {eff }}$ is the effective volume [21] and $\lambda_{t}$ is the initiation density defined by

$$
\lambda_{t}\left(\sigma_{F}\right)=\lambda_{0}\left(\frac{\sigma_{F}}{S_{0}}\right)^{m}
$$

where $m$ is the Weibull modulus, $S_{0}^{m} / \lambda_{0}$ is the Weibull scale parameter, and $\sigma_{F}$ is the maximum principal stress in the whole domain. The effective volume, $Z_{\text {eff }}$, is expressed as

$$
Z_{\text {eff }}=Z H_{m}
$$

where $Z$ is the size of the whole volume and $H_{m}$ the stress heterogeneity factor [22] written as

$$
H_{m}=\frac{1}{Z} \int_{\Omega}\left(\frac{\left\langle\sigma_{1}\right\rangle}{\sigma_{F}}\right)^{m} d Z, \quad \text { when } \sigma_{F}>0 \text {. }
$$

In (5), $\sigma_{1}$ is the local maximum principal stress and $\langle\bullet\rangle$ Macaulay's brackets. The stress heterogeneity factor characterizes the effect of the load pattern on the cumulative failure probability. Last, the average failure stress $\sigma_{w}$ and the corresponding standard deviation $\sigma_{\text {sd }}$ are written as

$$
\begin{aligned}
\sigma_{w} & =S_{0}\left(\lambda_{0} Z H_{m}\right)^{-1 / m} \Gamma\left(1+\frac{1}{m}\right), \\
\sigma_{\mathrm{sd}} & =S_{0}\left(\lambda_{0} Z H_{m}\right)^{-1 / m} \sqrt{\Gamma\left(1+\frac{2}{m}\right)-\Gamma^{2}\left(1+\frac{1}{m}\right)},
\end{aligned}
$$

where $\Gamma$ is the Euler function of the second kind

$$
\Gamma(1+x)=\int_{0}^{\infty} \exp (-u) u^{x} d u
$$

Under high strain rate conditions, such as the situation during a spalling test, several cracks are initiated and propagate from the initial defects leading to multiple fragmentation. In that case, while the weakest defect is activated and the resulting crack propagates, several other cracks are initiated during this time. In contrast to the low loading rate conditions that characterize the fracture process in general (with the consequence of the initiation and growth of a single crack leading to fracture of the whole structure), when the loading rate is high there is enough time for the stress to reach high levels and activate smaller (or stronger) defects. When a crack is propagating at a very high velocity (a portion of the stress wave velocity), it relaxes the stresses in its vicinity. The multiple fragmentation process with multiple cracks growing at the same time stops when the whole structure is covered by these relaxed stress regions (see Figure 6).

The interaction law between cracks already initiated and the critical defects of the material is given by the concept of probability of nonobscuration $P_{\text {no }}[6,7]$. In the case of multiple fragmentations, the interaction between the horizon (the 


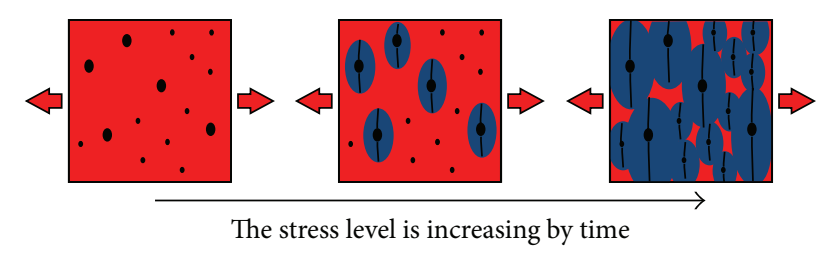

FIgURE 6: Obscuration phenomenon and multiple fragmentation process.

region around a crack where stresses are relaxed due to crack opening) and the boundary of the domain $\Omega$ is small and if a uniform stress field is assumed, the obscuration probability $P_{o}$ is written as [6]

$$
\begin{aligned}
P_{o}(T) & =1-P_{\text {no }}(T) \\
& =1-\exp \left(-\int_{0}^{T} \frac{d \lambda_{t}}{d t}[\sigma(t)] Z_{o}(T-t) d t\right) .
\end{aligned}
$$

In (9), $Z_{o}$ is the obscured zone, $\sigma$ the local eigenstress component, $T$ the current time, and $t$ the crack initiation time. The probability of obscuration is defined for each eigendirection $i$ and the change of $P_{o i}$ is expressed in differential form, in order to be employed in an FE code using (9), as

$$
\begin{aligned}
& \frac{d^{2}}{d t^{2}}\left(\frac{1}{1-P_{o i}} \frac{d P_{o i}}{d t}\right)=3 ! S\left(k C_{0}\right)^{3} \lambda_{t}\left[\sigma_{i}(t)\right] \\
& \text { when } \frac{d \sigma_{i}}{d t}>0, \sigma_{i}>0,
\end{aligned}
$$

where $\sigma_{i}$ is the local eigenstress component, $S$ is a shape parameter (equal to $4 \pi / 3$ when the obscuration volume is similar to a sphere in $3 \mathrm{D}), k$ is a constant parameter $(k=0.38$ when the crack length becomes significantly larger than the initial size), and $C_{0}$ is the $1 \mathrm{D}$ wave speed.

More recently, Erzar and Forquin [17] have investigated the postpeak tensile behavior of concrete by means of Monte Carlo calculations and tensile experiments performed on damaged but unbroken spalled samples. An improvement of the modeling was proposed based on the following statement: despite the propagation of the unstable cracks in the specimen, there is still a cohesive stress in the vicinity of these triggered cracks that controls the whole softening behavior of the material. Therefore a cohesive model is combined with the DFH model to describe the cohesive stress in the obscured zone and the softening behavior of geomaterials in dynamic tension $[19,20]$. In the cohesive model, an extra term is added to the macroscopic stress $\Sigma_{i}$ as

$$
\Sigma_{i}=\left(1-P_{o i}\right) \sigma_{i}+\left(P_{o i}\right)^{\alpha_{D}} \sigma_{\mathrm{coh}}(\varepsilon)=\left(1-D_{i}\right) \sigma_{i}
$$

where $\sigma_{\text {coh }}$ is the residual strength in the obscuration zone yielding

$$
\sigma_{\mathrm{coh}}=\sigma_{o}^{d} \exp \left(-\left(\frac{\varepsilon}{\varepsilon_{0}^{d}}\right)^{n_{d}}\right)
$$

TABLE 1: Material parameters used in the DFH material model.

\section{Mechanical parameters}

$v$

DFH model parameters

Weibull parameters

$m$

$\sigma_{w}(\mathrm{MPa})$

$\sigma_{\text {sd }}(\mathrm{MPa})$

$Z_{\text {eff }}\left(\mathrm{mm}^{3}\right)$

Obscuration volume parameters

$S$

$k$

In (12) $\alpha_{D}, \sigma_{o}^{d}, \varepsilon_{0}^{d}$, and $n_{d}$ are material-dependent parameters and $D_{i}$ is the damage variable defined for each principal direction. The cohesive term can be seen as an extra contribution related to the fracture energy of the material. It enforces the final failure of an element to occur when the dissipated energy due to the damage process reaches the fracture energy of the material.

In the eigenstress frame, the compliance tensor is defined by

$$
\left[\begin{array}{l}
\varepsilon_{1} \\
\varepsilon_{2} \\
\varepsilon_{3}
\end{array}\right]=\frac{1}{E}\left[\begin{array}{ccc}
\frac{1}{1-D_{1}} & -v & -v \\
-\nu & \frac{1}{1-D_{2}} & -v \\
-\nu & -v & \frac{1}{1-D_{3}}
\end{array}\right]\left[\begin{array}{c}
\Sigma_{1} \\
\Sigma_{2} \\
\Sigma_{3}
\end{array}\right]
$$

where $\varepsilon_{1}, \varepsilon_{2}$, and $\varepsilon_{3}$ are the principal strains and $E$ and $v$ are Young's modulus and Poisson's ratio of the undamaged material, respectively.

In the numerical analysis discussed below, the Bohus granite rock characterized in [15] is considered. Explicit values of the material parameters are presented in Table 1 . The cohesion model parameters are calibrated based on the results of the spalling tests and are reported later in the next section.

At high strain rates, the ultimate strength is deterministic and is obtained from the DFH model as a function of the Weibull parameters as

$$
\Sigma^{u}=\sigma_{c}\left(\frac{1}{e} \frac{(m+n-1) !}{m ! n !}\right)^{1 /(m+n)},
$$

where $n$ is the medium dimension $(n=3$ in $3 \mathrm{D})$ and $\sigma_{c}$ a characteristic stress as

$$
\sigma_{c}=\left(S_{0} \lambda_{0}^{-1 / m}\right)^{m /(m+n)}(\dot{\sigma})^{m /(m+n)}\left(S^{1 / n} k C\right)^{-n /(m+n)} .
$$

It should be mentioned that the DFH model predicts the granite tensile strength at the strain rate of $701 / \mathrm{s}$ (the same strain rate as in the spalling test discussed earlier) as $19.5 \mathrm{MPa}$ which is fairly close to the experimental result, 18.9 MPa. The material parameters used for this calculation are taken from Table 1. It should also be mentioned that the effective volume in this calculation is the volume of the cylindrical specimen 
that is used in the spalling tests and therefore the average failure stress and the standard deviation should be scaled based on the Weibull size effect.

The material strain rate sensitivity can be described by the DFH model using a multiscale description that is probabilistic at low strain rates and deterministic at high strain rates [7]. Equation (10) is valid for a multiple fragmentation phenomenon at a high stress rate. In order to cover both single and multiple fragmentation processes using the same finite element (FE) code, the defect density function is modified as $[6,7]$

$$
\hat{\lambda}_{t}\left[\sigma_{i}(t)\right]= \begin{cases}0, & \text { if } \sigma_{F}(t) \leq \sigma_{k}, \\ \lambda_{0}\left(\frac{\sigma_{i}(t)}{S_{0}}\right)^{m}, & \text { otherwise, }\end{cases}
$$

where $\sigma_{k}$ is the random stress generated for each finite element according to Weibull law. A more detailed description of the multiscale model can be found in [7]. To show the prediction of the model in the whole range of strain rates, three values of $\sigma_{k}$ are considered and the model prediction is plotted in Figure 7.

\subsection{Modeling of the Spalling Test and Determining the Cohesive} Model Parameters. The equation of motion is discretized using the FE method and the explicit time integration scheme is employed. The numerical simulation of the spalling tests is carried through with the DFH material model implemented as a VUMAT subroutine in the ABAQUS/Explicit software [23]. The finite element mesh used in the simulation of spalling tests is shown in Figure 8 using 8-node linear elements with reduced integration.

First the original DFH model with no cohesion is employed and the results are compared with the experiments. Later on, a cohesive strength is added to the original model to more realistically deal with the softening behavior of the material at dynamic loading. A parameter study is performed to obtain the cohesive model parameters that forms a best fit to the experimental results. It can be seen that adding the cohesive model makes the results more realistic and closer to the experimental results (see Figure 9). The cohesive model parameters are summarized in Table 2. Furthermore, the axial strain from the numerical model is compared with the gauges measurement and good agreement is obtained (see Figure 10).

\subsection{Modeling of the Spalling Test with Preexisting Structural} Cracks. The numerical modeling of the spalling tests with preexisting structural cracks is performed. As the state of the initial damage in each specimen is not completely clear, a set of numerical analyses is needed to define this state for each test. This calibration stage mainly includes changing the amount of the preexisting cracks to obtain the similar stiffness reduction as the specimen that reflects itself mainly in the postpeak part in the rear face velocity profile.

Figure 11 shows the initial damage state used in the numerical simulation of the specimen with preexisting cracks (the corresponding experimental results for this specimen are discussed in Section 2.3). The initial cracks in the numerical

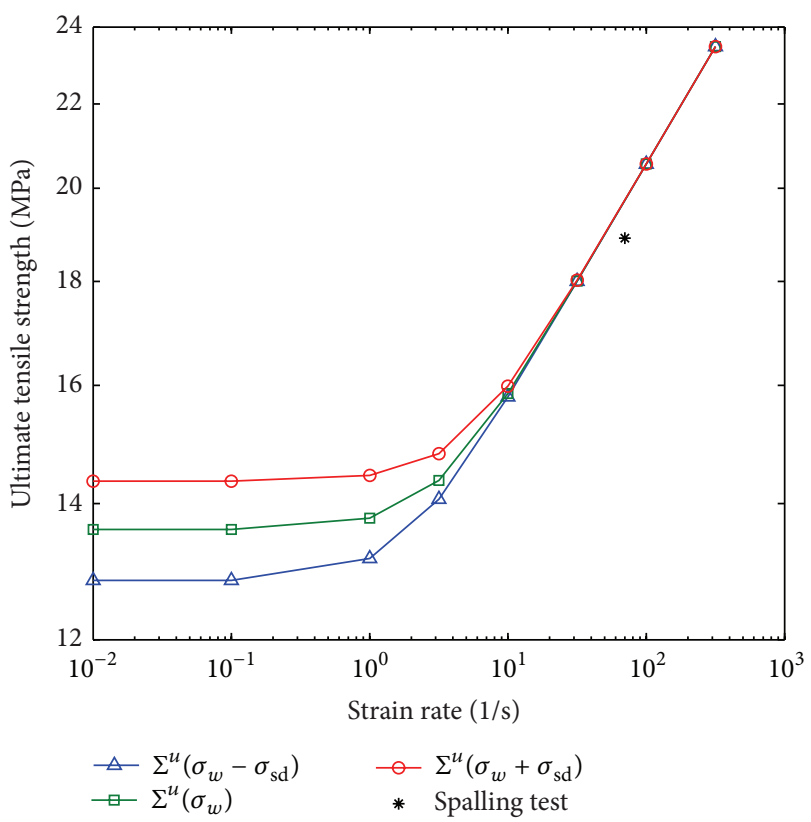

FIGURE 7: Ultimate strength in granite as a function of the strain rate in logarithmic scale based on the DFH model using the multiscale description and three values of random stress $\sigma_{k}$.

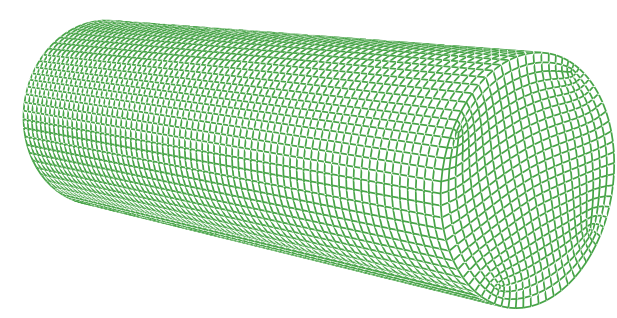

FIGURE 8: FE mesh used in the simulations of spalling tests with 38,000 8-noded elements.

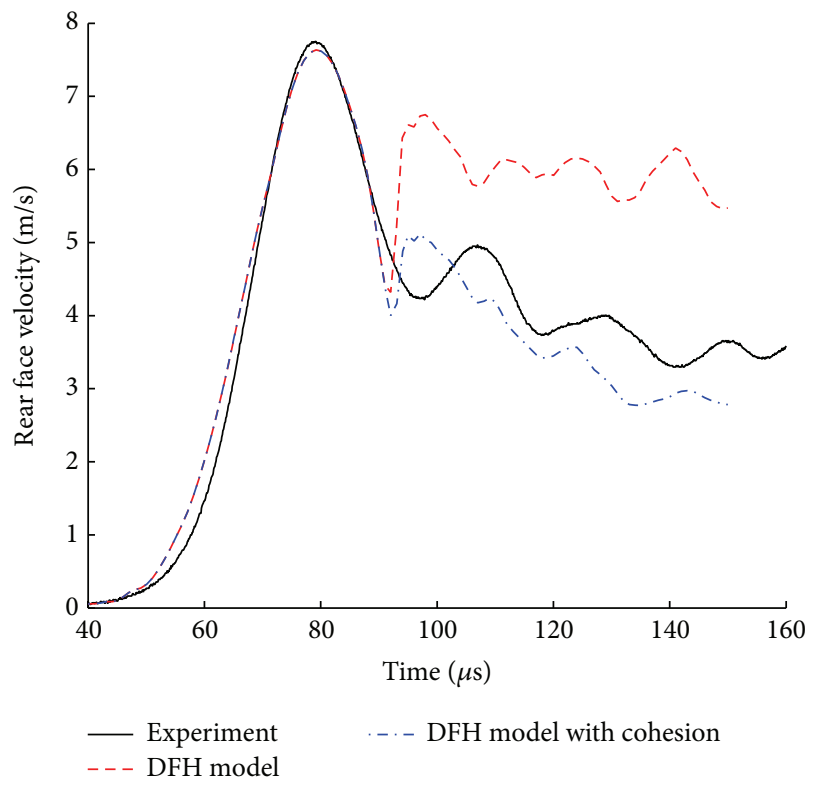

FIGURE 9: Finite element and experimental results from the spalling test for rear face velocity. 
TABLE 2: Material parameters used in the cohesion model.

\begin{tabular}{lc}
\hline Cohesion model parameters & \\
$\alpha_{D}$ & 1.5 \\
$\sigma_{o}^{d}(\mathrm{MPa})$ & 12 \\
$\varepsilon_{0}^{d}$ & 0.01 \\
$n_{d}$ & 1 \\
\hline
\end{tabular}

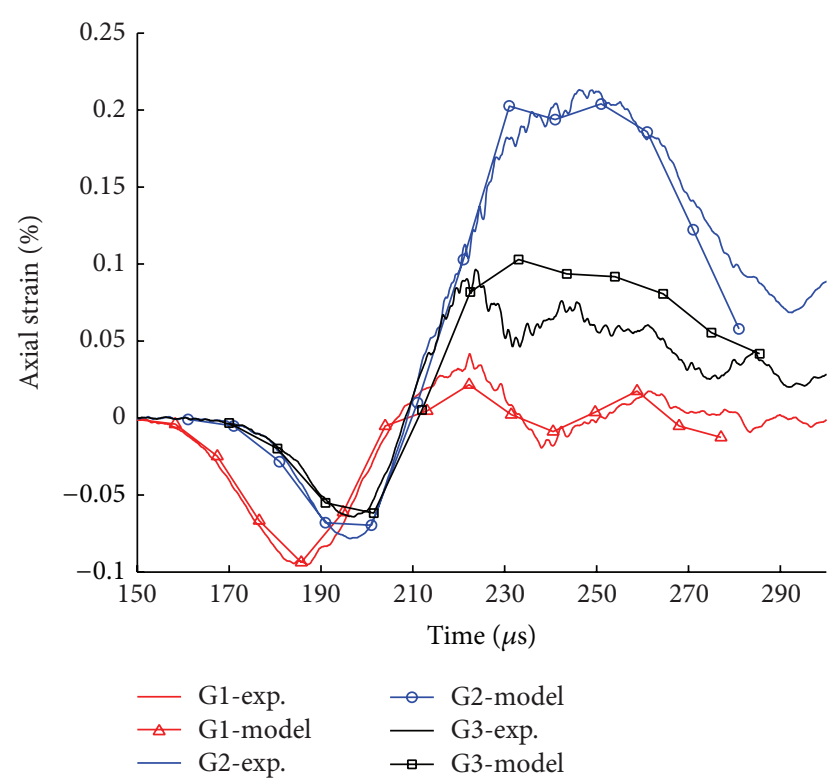

FIGURE 10: Finite element and experimental results from the spalling test for axial strain.

model consist of sets of elements with negligible tensile strength that leads to their immediate failure (the damage value becomes unity) when loaded in tension. They can still carry compressive loads when crack closure occurs due to compressive stresses. The numerical approach is described in detail in [14]. It should be mentioned that the quantity and length of these structural cracks do not necessarily correspond to the real situation in the specimen. Therefore only the total initial damage is calibrated based on the stiffness reduction occurring in the experimental results. The comparison between the experimental and numerical results is shown in Figure 12. The results with the preexisting cracks are in a better agreement with the experimental ones.

Furthermore, a numerical (FEM) quasi-static tensile test is performed on the specimen with initial damage state according to Figure 11 and an effective stiffness of about $35 \mathrm{GPa}$ is obtained. This is fairly close to the average stiffness from the quasi-static tensile tests that is performed on some of the specimens with preexisting cracks as discussed earlier. This further indicates that the state of initial damage in the numerical simulation is of the correct order.

\section{Conclusions}

The rate dependency of tensile strength in granite with and without preexisting cracks is investigated by means of spalling

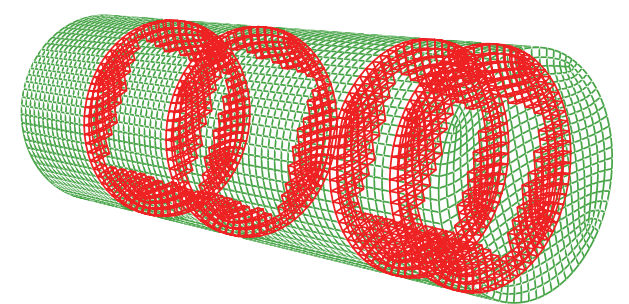

FIGURE 11: Preexisting structural cracks in the analyzed specimen. The finite element mesh is also shown.

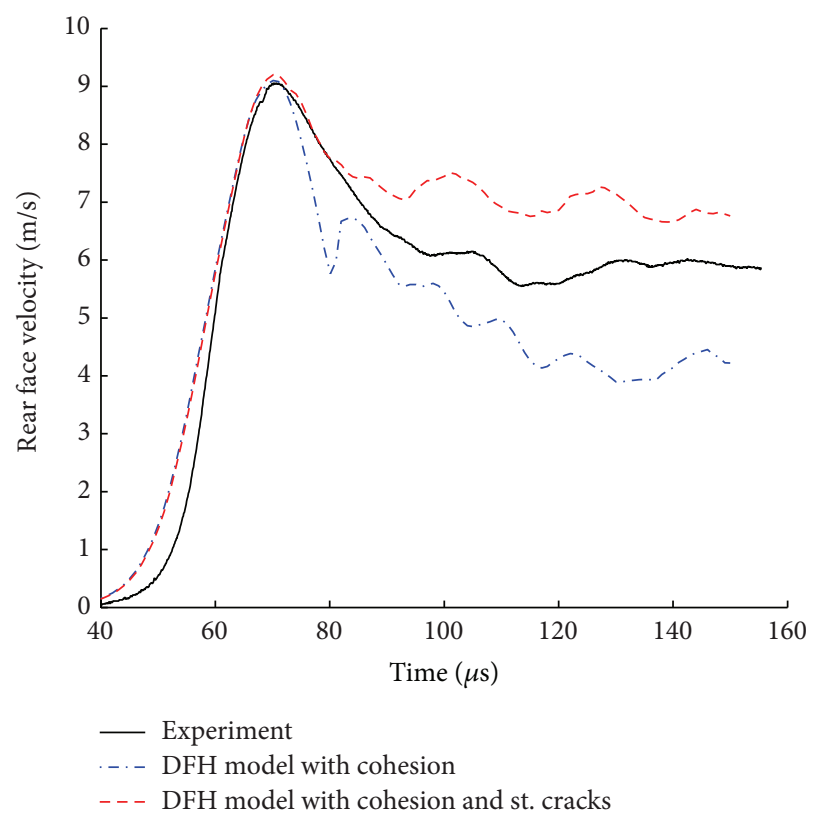

FIGURE 12: Finite element and experimental spalling test results. Preexisting structural cracks are present in the simulations.

experiments. Considerable strain rate dependency of the tensile strength is obtained at strain rates of about $10^{2} 1 / \mathrm{s}$, this loading rate being pertinent to the situation of rock materials at percussive drilling, which is the application of interest in this investigation. For instance, a dynamic tensile strength of $18.9 \mathrm{MPa}$ is obtained at a strain rate of $70 \mathrm{l} / \mathrm{s}$ in a sample without preexisting cracks. This is more than twice the tensile strength of the specimen (with the same size) at quasi-static conditions, which is $8 \mathrm{MPa}$.

The DFH anisotropic damage model is used to explain the material response at dynamic loading. The DFH model allows predicting the dynamic tensile strength at strain rate of $701 / \mathrm{s}$ of $19.5 \mathrm{MPa}$ which is fairly close to the experimental results.

Some specimens are exposed to coarser mechanical loading during the cutting process and new cracks, called structural cracks in this work, are introduced in addition to the default material cracks and defects. It is shown that the mechanical response of the material changes dramatically during spalling test due to such preexisting cracks. The lower effective stiffness of these specimens, in tension, reflects itself in the asymmetric postpeak part in the rear face velocity profile. Also the rebounding phenomenon is not seen or is 
negligible in these specimens and the rear face velocity curve is more plateau-like in the postpeak section.

Numerical modeling (finite element modeling) of the spalling tests is performed. First the original DFH model with no cohesion is employed and the results are compared with the experiments. Later on, a cohesive strength is added to the original model to more realistically deal with the softening behavior of the material at dynamic loading. It is shown that adding the cohesive strength makes the results more realistic and closer to the experimental results.

Furthermore, two-scale numerical modeling (FEM) of the spalling tests accounting for preexisting structural cracks is performed. As the state of the initial damage in each specimen is not completely clear, a first set of numerical analyses is conducted to define this state for each test. The initial cracks are introduced in the numerical model by selecting sets of elements and allocating them negligible tensile strength that leads to their immediate failure when loaded in tension. They can still carry compressive loads when crack closure occurs due to compressive stresses. It is shown that adding such cracks leads to results more similar to the experimental ones.

\section{Competing Interests}

The authors declare that there are no competing interests regarding the publication of this paper.

\section{References}

[1] J. Weerheijm, Concrete under impact tensile loading and lateral compression [Ph.D. thesis], Delft University, 1992.

[2] J. R. Klepaczko and A. Brara, "An experimental method for dynamic tensile testing of concrete by spalling," International Journal of Impact Engineering, vol. 25, no. 4, pp. 387-409, 2001.

[3] H. Schuler, C. Mayrhofer, and K. Thoma, "Spall experiments for the measurement of the tensile strength and fracture energy of concrete at high strain rates," International Journal of Impact Engineering, vol. 32, no. 10, pp. 1635-1650, 2006.

[4] B. Erzar and P. Forquin, "An experimental method to determine the tensile strength of concrete at high rates of strain," Experimental Mechanics, vol. 50, no. 7, pp. 941-955, 2010.

[5] J. Weerheijm and J. C. A. M. Van Doormaal, “Tensile failure of concrete at high loading rates: new test data on strength and fracture energy from instrumented spalling tests," International Journal of Impact Engineering, vol. 34, no. 3, pp. 609-626, 2007.

[6] C. Denoual and F. Hild, "A damage model for the dynamic fragmentation of brittle solids," Computer Methods in Applied Mechanics and Engineering, vol. 183, no. 3-4, pp. 247-258, 2000.

[7] P. Forquin and F. Hild, "A probabilistic damage model of the dynamic fragmentation process in brittle materials," Advances in Applied Mechanics, vol. 44, pp. 1-72, 2010.

[8] A. J. Zielinski, Fracture of Concrete and Mortar Under Uniaxial Impact Tensile Loading, 1982.

[9] O. K. Mahabadi, B. E. Cottrell, and G. Grasselli, "An example of realistic modelling of rock dynamics problems: FEM/DEM simulation of dynamic Brazilian test on barre granite," Rock Mechanics and Rock Engineering, vol. 43, no. 6, pp. 707-716, 2010.

[10] T. Saksala, M. Hokka, V.-T. Kuokkala, and J. Mäkinen, "Numerical modeling and experimentation of dynamic Brazilian disc test on Kuru granite," International Journal of Rock Mechanics and Mining Sciences, vol. 59, pp. 128-138, 2013.

[11] R. D. Krieg, "A simple constitutive description for soils and crushable foams," Report SC-DR-7260883, Sandia National Laboratories, Albuquerque, NM, USA, 1978.

[12] D. V. Swenson and L. M. Taylor, "A finite element model for the analysis of tailored pulse stimulation of boreholes," International Journal for Numerical and Analytical Methods in Geomechanics, vol. 7, no. 4, pp. 469-484, 1983.

[13] M. Saadati, P. Forquin, K. Weddfelt, P. L. Larsson, and F. Hild, "Granite rock fragmentation at percussive drillingexperimental and numerical investigation," International Journal for Numerical and Analytical Methods in Geomechanics, vol. 38, no. 8, pp. 828-843, 2014.

[14] M. Saadati, P. Forquin, K. Weddfelt, P.-L. Larsson, and F. Hild, "A numerical study of the influence from pre-existing cracks on granite rock fragmentation at percussive drilling," International Journal for Numerical and Analytical Methods in Geomechanics, vol. 39, no. 5, pp. 558-570, 2015.

[15] M. Saadati, On the mechanical behavior of granite: constitutive modeling and application to precussive drilling [Doctoral thesis], Department of Solid Mechanics, KTH, Stockholm, Sweden.

[16] L. Sallier and P. Forquin, "Influence of the confined behaviour and the tensile strength of concrete slabs under projectileimpact," in Dynamic Behavior of Materials, vol. 1, pp. 567-571, Springer, Berlin, Germany, 2013.

[17] B. Erzar and P. Forquin, "Analysis and modelling of the cohesion strength of concrete at high strain-rates," International Journal of Solids and Structures, vol. 51, no. 14, pp. 2559-2574, 2014.

[18] S. A. Novikov, I. I. Divnov, and A. G. Ivanov, "Investigation of the fracture of steel, aluminum and copper under explosive loading," Fizika Metallov i Metallovedenie, vol. 21, pp. 608-615, 1966.

[19] W. Weibull, "A statistical theory of the strength of materials," Report 151, Royal Institute of Technology, Stockholm, Sweden, 1939.

[20] W. Weibull, "A statistical distribution function of wide applicability," Journal of Applied Mechanics, vol. 18, no. 3, pp. 293-297, 1951.

[21] D. G. S. Davies, "The Statistical Approach to Engineering Design in Ceramics," Proceedings of the British Ceramic Society, vol. 22, no. 6, pp. 429-452, 1973.

[22] F. Hild, R. Billardon, and D. Marquis, "Hétérogénéité des contraintes et rupture des matériaux fragiles," Comptes Rendus de l'Académie des Sciences. Série 2, Mécanique, Physique, Chimie, Sciences de l'Univers, Sciences de la Terre, vol. 315, no. 11, pp. 1293-1298, 1992.

[23] Abaqus 6.11, Dassault Systèmes Simulia, Providence, RI, USA, 2011. 

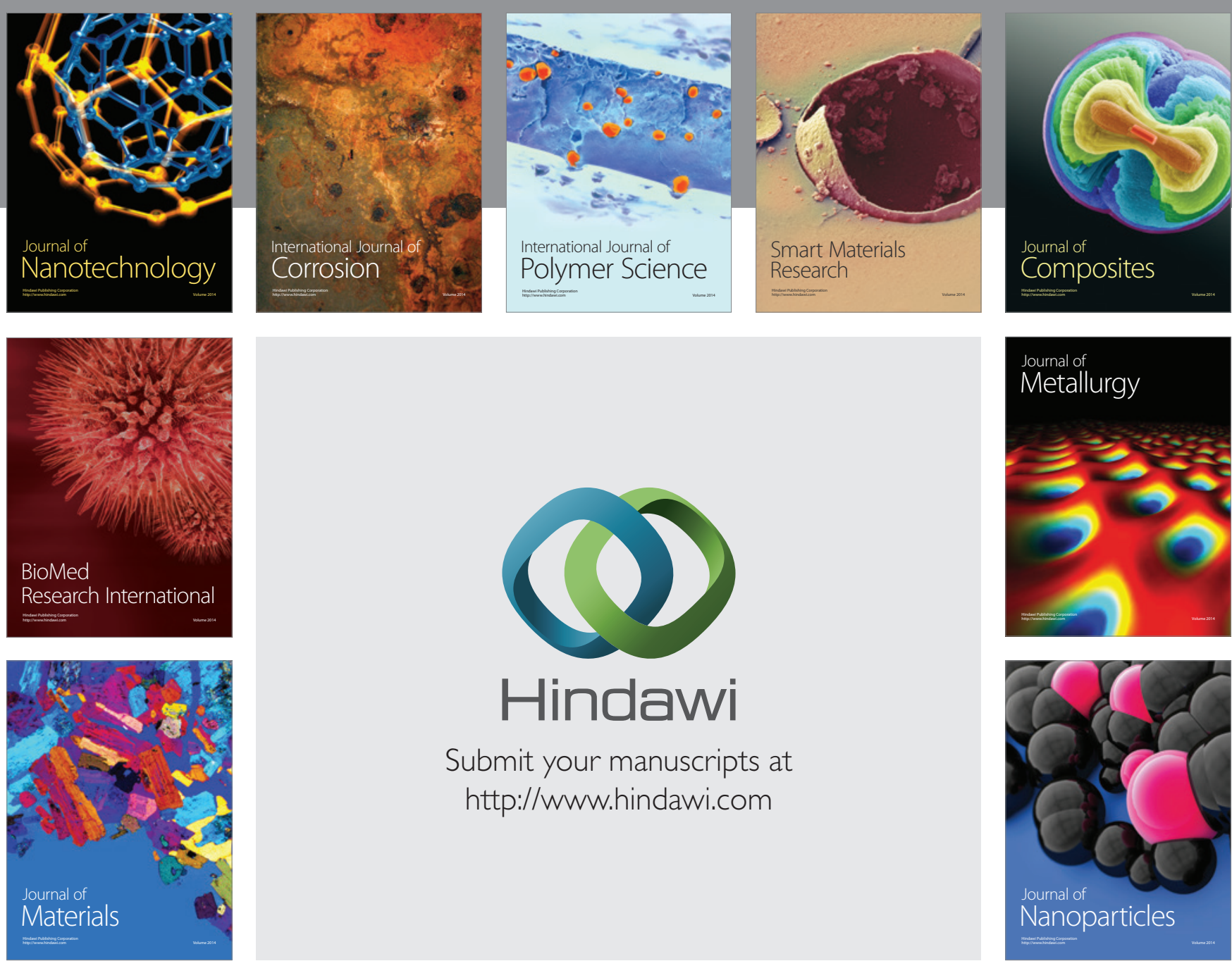

\section{Hindawi}

Submit your manuscripts at

http://www.hindawi.com

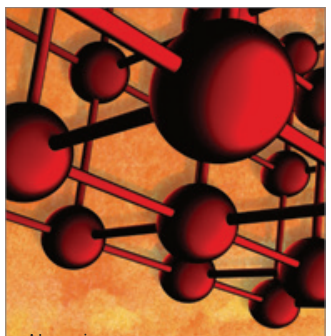

Materials Science and Engineering
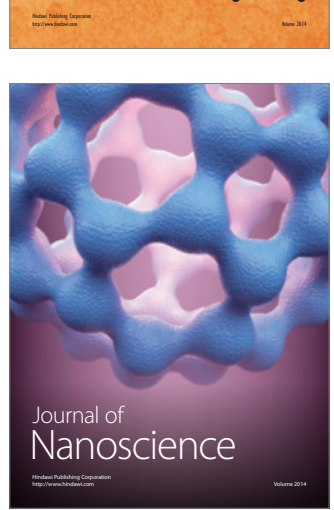
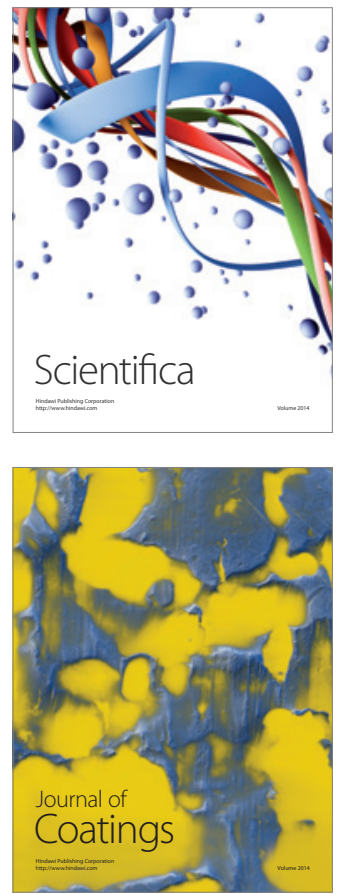
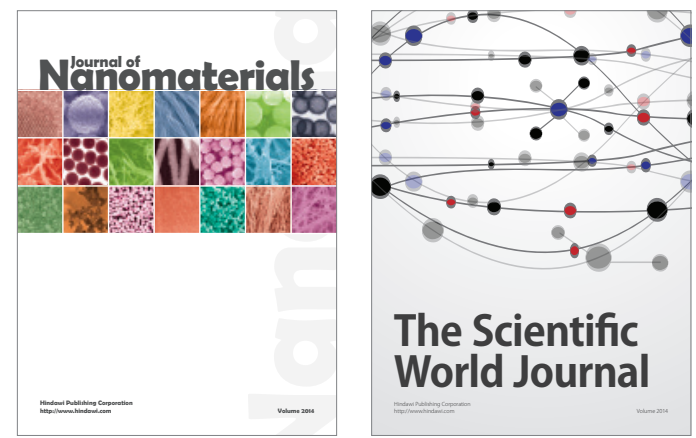

The Scientific World Journal
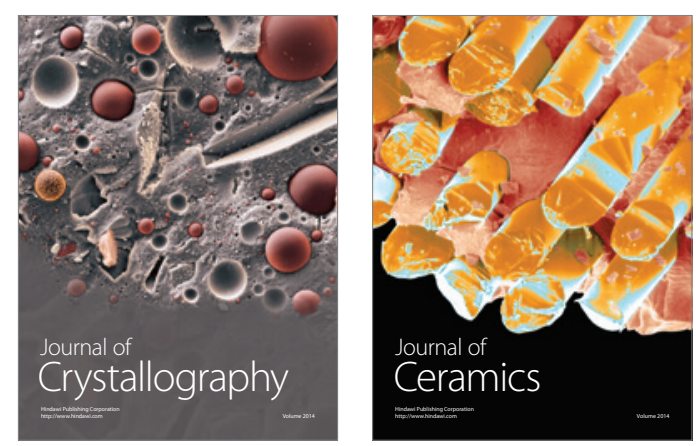
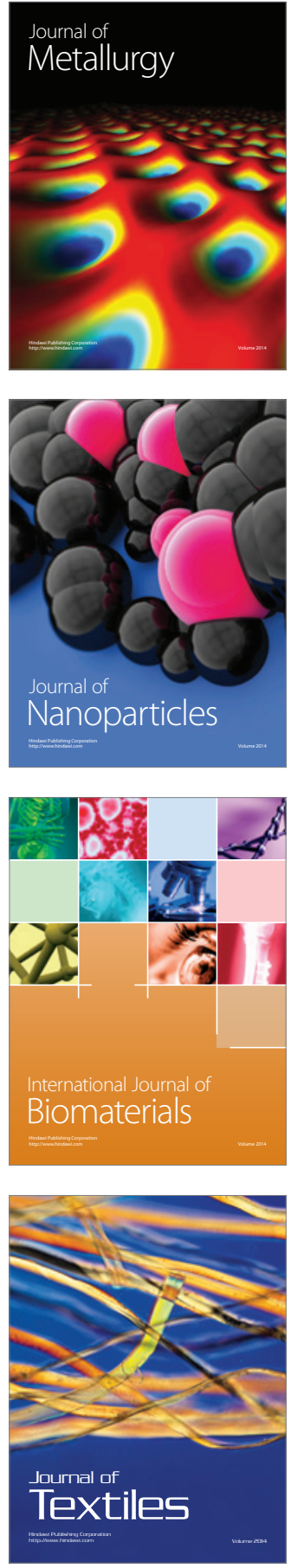